\title{
Pleural Malignant Mesothelioma pNX TNM Finding v8
}

National Cancer Institute

\section{Source}

National Cancer Institute. Pleural Malignant Mesothelioma pNX TNM Finding v8. NCI

Thesaurus. Code C136395.

Pleural malignant mesothelioma in which the regional lymph nodes cannot be assessed.

(from AJCC 8th Ed.) 